\title{
A PESQUISA EM EDUCAÇÃO FÍSICA NO BRASIL: AVALIANDO AVALIAÇÕES
}

Aguinaldo Gonçalves

\section{Resumo}

“Avaliação da produção científica em Educação Física/ Ciências do Esporte”, publicação temática da Revista Brasileira de Ciências do Esporte, é tomada como objeto de análise. Pontuam-se e discutem-se aspectos polêmicos das questões aí consideradas: especificamente quanto a onde publicar, se a nível nacional ou internacional, insinuam-se destaques como respectivos rigor, ideologia e evolução. Também merecem atenção a lentidão de publicação, a pretensa dicotomia da área e mesmo o antagonismo entre o livro e o periódico como opção preferencial.

\section{Palavras-Chave}

Produção científica; Educação Física; Avaliação.

\section{RESEARCH ON PHYSICAL EDUCATION IN BRAZIL: EVALUATING EVALUATIONS}

\section{Aguinaldo Gonçalves}

\begin{abstract}
"Assessment on the scientific production on Physical Education/Sports Science", thematic publication from Brazilian Journal of Sport Science, is considered for analysis. Controversial topics are therewith treated, such as where to publish (if at national or international level), in terms of rigour, ideology and evolution. Also attention is paid to publishing delay, alleged dichotomy of the area between Human and Natural Sciences and the antagonism between book and paper as prefered option.
\end{abstract}

\section{Key-Words}

Scientific production; Physical Education; Evaluation.

\section{LA INVESTIGACIÓN DE EDUCACIÓN FÍSICA EN BRASIL: EVALUANDO EVALUACIONES}

\section{Resumen}

"Evaluación de la producción científica en Educación Física/Ciencias del Deporte”, una publicación temática de la 'Revista Brasileira de Ciências do Esporte' (Revista Brasilera de Ciencias del Deporte), se toma como objeto de análisis. Se apuntan y se discuten aspectos polémicos de las cuestiones allá consideradas: específicamente cuanto a dónde publicar, si a escala nacional o internacional, se insinúan destaques como respectivos rigor, ideología y evolución. También merecen atención la lentitud de publicación, la supuesta dicotomía del área e incluso el antagonismo entre el libro y el periódico como opción preferente.

\section{Palabras-Clave}

Producción científica; Educación Física; Evaluación. 
A Revista Brasileira de Ciências do Esporte dedica fascículo próprio (ISSN 0101-3289, setembro de 2007) à Avaliação da Produção Científica em Educação Física/Ciências do Esporte, agregando desde pronto no Editorial formulado pelos próprios Editores, que a matéria "ganha maior visibilidade na atualidade com a consolidação do sistema de avaliação da CAPES (...)”. Em outros termos, autores e leitores aderem ao truísmo aí embutido de que, na cena acadêmica brasileira, produção intelectual e pós-graduação estão inextricavelmente ligados, conformadas pela mediação normativa das gestões periódicas da CAPES.

Cabe, já num primeiro momento, a parabenização à iniciativa pelo mérito de, em assim fazendo, contribuir substantivamente para o desenvolvimento da área, bem como confesso a satisfação pela expansão do interesse para com esse tema/aplicação de pesquisa, em que minha militância há mais de vinte anos foi relativamente fato isolado, ao produzir os primeiros dados sobre série histórica de indicadores de produtividade, segundo temática, instrumento de fomento, instituição de origem e abrangência, quando criamos e iniciamos a condução da área no interior do Conselho Nacional de Desenvolvimento Científico e Tecnológico (GONÇALVES; VIEIRA, 1989). Hoje, constata-se, só na mencionada publicação, são mais de uma dúzia de estudiosos, cada qual com seus recursos, buscando situar-se no assunto tornado tormentoso.

De fato, trata-se de coletânea de textos que merece ser apreciada, a encerrar alguns equívocos/impropriedades que demandam ser apontados, até a bem de sua justa valorização. Com vistas a prevenção de pleonasmo, permito-me mencionar apenas um reparo em cada segmento. Do primeiro apresentado, o texto do Prof. Go Tani, algo que chama a atenção é sua afirmação à página 15 de que “ [...] Portanto, seria altamente salutar uma pesquisa em torno de um tema de interesse local ser avaliada, por exemplo, com o mesmo rigor que se aplica à análise de um artigo nacional ou internacional." Sabemos, entrementes, à saciedade que não podemos mais ter o direito da ingenuidade de ignorar que o que caracteriza a análise internacional das publicações não é unicamente o rigor, mas também as relações corporativas do "colégio invisível” dos autores (GONÇALVES et al, 1994), i.e. o trânsito de influências e trocas que se entretece entre os especialistas envolvidos em diferentes países e seus respectivos interesses (VELHO,1985).

Hugo Lovisolo, reconhecido homem das Ciências Humanas na Educação Física, trabalha, a seguir, o tema, paradoxalmente, pela perspectiva quantitativa: no entanto, sua generalização à página 31 é tão imprópria quanto qualquer outra, inclusive esta que estou fazendo agora. Mas, enfim, o que ele afirma é que, para publicação em periódico internacional "podemos, portanto, jogar fora a originalidade para apostarmos na publicação quase garantida." Evitando argumentar por excepções, não foi isto que vimos acontecer mesmo 
recentemente quando discutimos "empowerment”, "advocacy”, “accountabilaty", "governance”, em programa de hidroginástica de mulheres brasileiras sedentárias em revista européia (VICENTIN et al, 2006).

A criativa produção do Prof. Carneiro Rodrigues (p. 35 a 48) sobre a metáfora do "tamanduá olímpico" também se expressa extremamente interessante, mas não se furta, de igual modo, no calor da argumentação, à afirmação nunca demonstrada, ao menos que se tenha notícia de que “ [...] a progressiva internacionalização da publicação em inglês pode liquidar de vez com as publicações regionais".

Jocimar Daólio ao se inspirar no cândido Machado de Assis dos conhecidos Esaú e Jacó, vem nos falar que "[...] A principal característica da pesquisa nas humanidades é justamente a lentidão inerente à construção de seu objeto de pesquisa e a conseqüente lentidão de seus procedimentos metodológicos", mencionando minudicentes exemplos de como esse tipo de pesquisa não pode operar sob o regime de hora marcada, em relação a investigações biológicas. Ora, seria acaciano citar tantas destas nas quais a observação dos fatos naturais também não se dá dessa forma, retardando, muitas vezes, a esperada obtenção de resultados. Para ficar apenas em exemplo próprio, quando nos interessamos por conhecer características biológicas, sobretudo citogenéticas, de famílias do Brasil Central portadoras de agravos constitucionais, foram necessários quase vinte anos para conseguirmos acumular informações sobre quase quatro mil unidades observacionais (SANTOS et al., 2004).

No mais, o eixo fulcral do pensamento desse autor repousa na dicotomia da Educação Física/ Ciências do Esporte, entre segmentos sócio-cultural e biodinâmica, perspectiva claramente superada nestes tempos de rupturas dos maniqueísmos dualistas, como virtuoso/pecaminoso, preventivo/curativo, qualitativo/quantitativo e do reconhecimento do complexo e da transversalidade (MORIN, 2001). No desempenho de nosso ofício, isto é cada dia mais sensível, ou contrariamente, não seriam possíveis atuações tão capitais como Treinamento e Condicionamento, Educação Física Adaptada, Recreação e Lazer e Qualidade de Vida, ou outras entre muitas que se queiram escolher.

A elegia ao livro procedida na seqüência por Carvalho e Manoel (p. 61-73) expressa tremendo paradoxo: 1/3 da produção da área se veicula por esse instrumento clássico, enquanto só a cidade de Bueno Aires, referem, tem mais livrarias que todo o território brasileiro. Diante dessa realidade, para que lado encaminhar as respectivas prioridades? Insistir com Gonçalves (2001) que conclama pela necessidade de melhorar-lhe a distribuição social, lembrando o famoso mote de Castro Alves "Oh! Bendito o que semeia livros...", ou investir ainda mais na temática e apoiar resolutamente as revistas eletrônicas na substituição dos periódicos 
em papel, já por definição, muito mais ágeis e velozes na condução da informação técnica contemporânea, ao menos na forma com que ainda se apresentam em nossos dias? De qualquer sorte, aí é obviado equívoco bastante perceptível por, na busca pela valorização, mencionarem os autores que a relevância do livro decorre de consistir em instrumento básico para a pós-graduação em Educação Física no país. Ora, básico, também desde logo é algo que para existir tem por identidade a dependência de especializações e tais coisas não necessariamente são encontradas em livros! Mais que perceptível é querer dimensionar a profundidade de um artigo científico à medida que ele se comporte como livro, para tornar-se "meu artigo de cabeceira" (p. 67): realmente, gerar reflexão, estimular especulações e transcender seu tempo e espaço,fatos tão marcadamente mencionados pelos autores, não constituem singularidade a excluir comunicações em periódicos.

Contrariando o modelo inicialmente definido de destacar apenas uma impropriedade por texto apresentado, no de Silva e Sacardo em suas "reflexões acerca da avaliação da pó-graduação brasileira..... na área da Educação Física", avulta, de imediato, a explicitação de investigar "como se configura as publicações científicas [...]" bem como, mais à frente surge a expressão “[...] cada programa de pós-graduação se direcione e se molde para serem avaliados"!

Sanches Gamboa et al. propõem-se a realizar, nas páginas seguintes, "balanço" e perspectivas da pesquisa na área no Nordeste brasileiro, no período de 1982 a 2004. Iniciando com ampla recuperação dos aspectos epistemiológicos envolvidos, evoluem com algumas peculiaridades, a saber:

i) apesar das numerosas conceituações que apresentam, não deixam claro o sentido que emprestam ao vocábulo "pesquisa”, empregado desde o título;

ii) como informam terem localizado 145 "pesquisas”, das quais 122 já defendidas, é-se levado a entender que assumiram os referidos autores o termo "pesquisa" como significando dissertação e teses;

iii) no entanto, apresentam informações relativas a apenas 70, pois, segundo referem, às demais não tiveram acesso, e

iv) consideram essa proporção 70/145 "número significativo". A dúvida principal que permanece é que o tratamento que encetam sobre o material colhido mira-os quanto a uma serie de indicativos, como distribuição por Estados de origem, áreas de titulação, grupos 
produtores e abordagem epistemológica, mas e a maioria absoluta que não foi considerada (75/145), como se comporta em relação a esses indicadores? Qual a particular razão por não figurarem no estudo?

Por último, no contexto tratado, cabe agregar que, comparando a visão de meus pares que visito diariamente com a leitura procedida deste volume analisado, mergulho em profunda consternação. Sim, é verdade: trata-se do pesar de constatar a abissal distância entre estas duas faces da realidade científica brasileira da Educação Física, a que julga e a que é julgada. Neste cenário o que encontro são diferentes figuras desse grupo, cada um a seu modo, embora, reunindo fatos e polemizando resultados; no outro, o que parece se expressar é marcado cartorialismo, onde detalhes são tornados importantes, posto que operados de forma hegemonicamente quantitativa. Até mesmo a consideração dos livros produzidos, no período em questão, conquista óbvia porém tardia, continua, confusamente, recurso secundário de avaliação, “experimental”na linguagem aí empregada!

Admito, no entanto, com naturalidade todo este quadro, considerando que a Educação Física é extremamente jovem enquanto área acadêmica (GONÇALVES, 1987): algumas décadas comparativamente a milênios cursados por outras mais tradicionais, como o Direito, a Engenharia ou a Medicina. Além disso, transita em seu interior, como vetor final, uma comunidade aguerrida que, com certeza encontrará o caminho para libertar-se dessas distorções e construir sua trajetória em direção à clareza e ao acerto. Por coerência, portanto, fica questionado o sentido de representatividade, e portanto de legitimidade, das informações consumidas a partir da obra em apreço, estimulando-se o avanço para a pluralidade que democratiza e legitima.

\section{REFERÊNCIAS}

GONÇALVES, A. Vestibular específico para a Educação Física: subsídios para uma decisão. Revista Brasileira Ciências Esporte, Campinas, v. 8, n. 2/3, p.181-185, 1988.

; VIEIRA, P. C. T. Uma caracterização da produção científica da área de Educação Física e

Esportes no Brasil: avaliação trienal de seu comportamento no âmbito do Conselho Nacional de Desenvolvimento Científico e Tecnológico. Revista Brasileira Ciências Esporte, Campinas, v. 10, n. 2, , p. 50 $-59,1989$.

.; GHIROTTO, F. M. S.; VIEIRA, P. C. T. Pós- graduação "hic et nunc”. Humanidades, Brasília v. 10, n. 1, p. 60-67, 1994. 
GONÇALVES, G. Caminhando na cidadania para além das incapacidades em hanseníase: atividade física a partir de unidade de referência do Sistema Único de Saúde. Dissertação (Mestrado em Educação Física)Faculdade de Educação Física, Universidade Estadual de Campinas, Campinas, 2001.

MORIN, E. A religação dos saberes: O desafio do século XXI. Rio de Janeiro, Bertrand Brasil, 2001.

SANTOS, M. et al., Genética Clínica no país: investigação de casuística de 3719 famílias. Revista Brasileira de Medicina, São Paulo, v. 61, n. 11, p. 707-710, 2004.

VELHO, L. Science on the periphery: a study of the agriculture scientific community in Brazilian universities. Thesis (Doctoral) - University of Sussex, Sussex, 1985.

VICENTIN, A . P. M.; PADOVANI, C. R.; GONÇALVES, A. The physiological and psychosocial effects of a 13 week hydrogymnastics program on healthy Brazilian women. Journal of Physical Education and Sport, v. 4, n. 1, 2006, p. 73-79, 2006. 


\section{Aguinaldo Gonçalves}

Faculdade de Educação Física/UNICAMP

\section{Referência do Artigo}

\section{ABNT}

GONÇALVES, A. A pesquisa em educação física no Brasil: avaliando avaliações. Conexões, v. 6, n. 3, p. 91-96, 2009.

\section{APA}

Gonçalves, A. (2009). A pesquisa em educação física no Brasil: avaliando avaliações. Conexões, 6 (3), 91-96.

\section{VANCOUVER}

Gonçalves A, A pesquisa em educação física no Brasil: avaliando avaliações. Conexões, 6(3), 91-96. 